\title{
Effects of lead and/or zinc exposure during the second stage of rapid postnatal brain growth on delta- aminolevulinate dehydratase and negative geotaxis of suckling rats
}

\section{E.C. Goulart ${ }^{1,2}$, \\ C.A.T. Pereira ${ }^{1}$, R.C. Garcia ${ }^{1}$, M.B.O. Giacomelli ${ }^{1}$ and A.L.S. Rodrigues ${ }^{2}$}

\author{
${ }^{1}$ Curso de Farmácia, Universidade do Sul de Santa Catarina, \\ Tubarão, SC, Brasil \\ ${ }^{2}$ Departamento de Bioquímica, Centro de Ciências Biológicas, \\ Universidade Federal de Santa Catarina, Florianópolis, SC, Brasil
}

\section{Correspondence \\ A.L.S. Rodrigues \\ Departamento de Bioquímica CCB, UFSC \\ 88040-900 Florianópolis, SC Brasil \\ Fax: +55-48-331-9672 \\ E-mail: analucia@mbox1.ufsc.br}

Received April 12, 2000

Accepted March 5, 2001

\section{Abstract}

Lead has been shown to produce cognitive and motor deficits in young rats that could be mediated, at least in part, by inhibition of the zinccontaining heme biosynthetic enzyme $\delta$-aminolevulinate dehydratase (ALA-D). In the present study we investigated the effects of lead and/ or zinc treatment during the second stage of rapid postnatal brain development on brain, kidney and blood ALA-D specific activity, as well as the negative geotaxis behavior of rats. Eight-day-old Wistar rats were injected intraperitoneally with saline, lead acetate $(8 \mathrm{mg} / \mathrm{kg})$ and/or zinc chloride ( $2 \mathrm{mg} / \mathrm{kg}$ ) daily for five consecutive days. Twentyfour hours after treatment, ALA-D activity was determined in the absence and presence of DL-dithiothreitol (DTT). The negative geotaxis behavior was assessed in 9- to 13-day-old rats. Treatment with lead and/or zinc did not affect body, brain or kidney weights or brainor kidney-to-body weight ratios of the animals. In spite of the absence of effect of any treatment on ALA-D specific activity in brain, kidney and blood, the reactivation index with DTT was higher in the groups treated with lead or lead + zinc than in the control group, in brain, kidney and blood (mean \pm SEM; brain: $33.33 \pm 4.34,38.90 \pm 8.24$, $13.67 \pm 3.41$; kidney: $33.50 \pm 2.97,37.60 \pm 2.67,15.80 \pm 2.66$; blood: $63.95 \pm 3.73,56.43 \pm 5.93,31.07 \pm 4.61$, respectively, $N=9-11)$. The negative geotaxis response behavior was not affected by lead and/or zinc treatment. The results indicate that lead and/or zinc treatment during the second stage of rapid postnatal brain growth affected ALA$\mathrm{D}$, but zinc was not sufficient to protect the enzyme from the effects of lead in brain, kidney and blood.
Lead is an environmental pollutant that accumulates with toxic effects in blood, liver, kidney and in the central nervous system of exposed mammals. The neurotoxicity of lead is of special interest, since cognitive and
Key words

- Lead acetate

- Delta-aminolevulinate dehydratase

- Negative geotaxis

- Postnatal brain growth
- Zinc chloride 
the kidneys, where it may cause proximal tubular dysfunction after acute exposure, or irreversible nephropathy that may lead to renal failure after chronic exposure (1).

Most of the studies concerning the toxic effects of lead are conducted in young rodents, which are generally exposed to the metal during the gestational and/or suckling periods (3). During the postnatal period rodents present three stages of rapid brain growth (4) in which they are especially prone to neurotoxicants $(5,6)$. However, there are few studies in the literature concerning the effects of lead on specific stages of postnatal brain development (6). Zinc has been shown to prevent hematological alterations induced by lead exposure (7) and has been proposed to prevent the neurotoxicity of lead (8). Additionally, a great deal of evidence has shown that zinc is a signaling molecule in the brain released by neural activity at many excitatory synapses (9). However, data on the effects of the administration of zinc, either alone or in combination with lead, on specific stages of rapid postnatal brain development are lacking.

There are many molecular targets for the action of lead. Lead has great affinity for sulfhydryl groups of endogenous biomolecules, which may contribute to its toxicity. It has been proposed that the toxicity of lead may be due, at least in part, to the inhibition of the sulfhydryl-containing enzyme $\delta$ aminolevulinate dehydratase (ALA-D) (1). This enzyme catalyzes the condensation of two $\delta$-aminolevulinic acid (ALA) molecules with the formation of porphobilinogen, which is a heme precursor. Consequently, ALA-D inhibition may impair heme biosynthesis and can lead to the accumulation of ALA, which may derange aerobic metabolism and may also have some pro-oxidant activity (10). ALA-D activity in erythrocytes is currently the most sensitive indicator of human exposure to lead (1). However, divergent results have been reported for ALA-D activity in the blood of lead-exposed animals, with data showing a reduction (7) or an increase $(6,11,12)$. Mammalian ALA-D has the peculiarity of having zinc as its cofactor (13). It has been demonstrated that zinc, as well as DL-dithiothreitol (DTT) in vitro, is able to restore the lead-inhibited ALA-D activity in rat and human blood (1,12-14). In addition, an antagonistic effect of zinc on the inhibition of ALA-D by lead in vivo has been reported (15), as well as the absence of an antagonistic effect (16). However, data are lacking regarding the ability of zinc to restore the normal activity of ALA-D inhibited by lead in vivo during a specific stage of rapid postnatal brain development.

In the present investigation, we examined the effects of lead and/or zinc exposure during the second stage of rapid postnatal brain development on brain ALA-D specific activity, the reactivation index of cerebral ALA-D with DTT, an indirect indicator of the ALA-D inhibition by lead and/or by the oxidation of critical sulfhydryl groups, and the negative geotaxis behavior of rats. ALA$D$ activity and the reactivation index with DTT were also assayed in blood and kidney of lead- and/or zinc-exposed rats.

Wistar rats of both sexes from our own breeding colony were used. Rats were maintained in an air conditioned room $\left(22-25^{\circ} \mathrm{C}\right)$ on a 12-h light/dark cycle with water and food available ad libitum. The breeding regimen consisted of grouping one virgin female (90-120 days of age) with one male for 20 days. Pregnancy was checked, and the pregnant rats were separated from the males. On the day of birth, litters were reduced to eight. When pups were 8 days old they started to receive one daily intraperitoneal (ip) injection of $8.0 \mathrm{mg} / \mathrm{kg}\left(\mathrm{CH}_{3} \mathrm{COO}\right)_{2} \mathrm{~Pb}$ or $2.0 \mathrm{mg} /$ $\mathrm{kg} \mathrm{ZnCl} 2$ alone or in combination. The control group received saline $(10 \mathrm{ml} / \mathrm{kg}$ body weight) for five consecutive days (8-12 days of age). The lead acetate dose was selected based on a previous study in which rats were exposed to lead acetate $(7.0 \mathrm{mg} / \mathrm{kg}$, subcutaneously, sc) during the same period of post- 
natal brain growth (6). The zinc dose was selected since it has been reported that zinc protects rats against the effects of lead on ALA-D at a dose 4-fold lower than the lead dose (7).

Rats were killed by decapitation under light ether anesthesia approximately $24 \mathrm{~h}$ after the end of treatment and blood was collected into heparinized tubes. Brain and kidney were quickly removed, placed on ice and then homogenized in 4 and 10 volumes of $150 \mathrm{mM} \mathrm{NaCl}$, respectively. The homogenate was centrifuged at $4000 \mathrm{~g}$ at $4^{\circ} \mathrm{C}$ for 10 min to yield a low-speed supernatant fraction to be used for enzyme assay.

ALA-D activity was assayed by measuring the rate of product (porphobilinogen) formation, according to the method of Sassa (17) except that $40 \mathrm{mM}$ sodium phosphate buffer, pH 6.4, and $4.0 \mathrm{mM}$ ALA were used. The reaction product was determined using modified Ehrlich's reagent at $555 \mathrm{~nm}$, with a molar absorption coefficient of $6.2 \times 10^{4} \mathrm{M}^{-1}$ $\mathrm{cm}^{-1}$ for the Ehrlich-porphobilinogen salt. The incubation was initiated by adding $36 \mu 1$ of the tissue preparation $(0.200-0.350 \mathrm{mg}$ of protein for brain and $0.150-0.350 \mathrm{mg}$ of protein for kidney) or blood (hemolyzed 1:4 in deionized water) to a final volume of 226 $\mu 1$. The incubation times were 3,2 and $1 \mathrm{~h}$, respectively. The temperature of incubation was $39^{\circ} \mathrm{C}$ for the cerebral and renal enzyme and $37^{\circ} \mathrm{C}$ for the blood enzyme. Simultaneously, a set of tubes was assayed under similar incubation conditions, except that 15 mM DTT was added in order to obtain the reactivation index as previously reported (14). Briefly, this index indicates the extent of the reactivation of ALA-D activity by DTT and is defined as follows:

$$
\begin{aligned}
& \text { (ALA-D activity with DTT - ALA-D activity } \\
& \text { without DTT) } \times 100
\end{aligned}
$$

ALA-D activity with DTT

Protein was determined by the method of Lowry et al. (18) using bovine serum albu- min as standard. Hematocrit was determined using a microcapillary centrifuge. ALA-D activity is reported as nmol porphobilinogen formed $\mathrm{h}^{-1} \mathrm{mg}$ protein $^{-1}$ for cerebral and renal ALA-D activity and as nmol porphobilinogen formed $\mathrm{h}^{-1} \mathrm{ml}$ erythrocytes ${ }^{-1}$ for the blood enzyme.

The negative geotaxis response was assessed from $24 \mathrm{~h}$ after the beginning of treatment (9-day-old rats) to 24 after the end of treatment (13-day-old rats), as described by Rocha et al. (5). After body weight measurement and just before daily lead acetate and/ or zinc chloride administration, pups were placed head down on an inclined plane $\left(30^{\circ}\right)$ and the latency to complete the geotaxis response was recorded. This test was repeated three times for each trial. If the pup did not satisfy this criterion within $60 \mathrm{~s}$, the trial was interrupted.

In order to exclude the possibility that any biochemical and/or behavioral effect of lead and/or zinc would be due to undernutrition associated with exposure to the metal, body, brain and kidney weights were assessed. The body weight of the animals (23.0 to $23.4 \mathrm{~g}$ ) was not altered by treatment (data not shown). Lead acetate and/or zinc chloride had no effect on brain weight (mean values ranged from 0.618 to $0.627 \mathrm{~g}$ ) or on kidney weight (mean values ranged from 0.248 to $0.294 \mathrm{~g}$; data not shown). The treatments also had no effect on organ-to-body weight ratios of brain (mean values ranged from 28.0 to $28.6 \mathrm{mg} / \mathrm{g}$ ) and kidney (mean values ranged from 11.1 to $13.7 \mathrm{mg} / \mathrm{g}$; data not shown). The absence of an effect of lead and/or zinc treatment on body, brain and kidney weights and on brain-to-body and kidney-to-body weight ratio is in agreement with results previously reported for rats exposed to 3.5 and $7.0 \mathrm{mg} / \mathrm{kg}(\mathrm{sc}$ ) lead acetate during the second stage of rapid postnatal growth (6). This finding indicates that our regimen of lead and/or zinc exposure did not produce gross physical alterations in rats. The hematocrit values of the rats exposed to 
saline, lead, zinc and lead + zinc were as follows: $31.3 \pm 0.89,28.9 \pm 0.61,30.6 \pm 0.78$ and $27.2 \pm 0.54$, respectively (mean \pm SEM; $\mathrm{N}=10$ ). One-way ANOVA followed by the Newman-Keuls test showed a reduction in hematocrit values in the groups treated with lead and with lead + zinc as compared to the control group $(\mathrm{F}(3,42)=6.38, \mathrm{P}<0.01)$. A reduction in hematocrit has also been previously reported in adult rats chronically exposed to lead (19), but, to our knowledge, has not been reported in young rats exposed to the metal during a specific stage of brain development which also corresponds to a period of intense tissue development. The reduction in the hematocrit of rats exposed to lead early during development seems to be a sensitive indicator of lead exposure and is not affected by zinc.

One-way ANOVA indicated no significant effect of lead and/or zinc treatment on specific ALA-D activity in brain $(\mathrm{F}(3,37)=$ $0.44, \mathrm{P}>0.05)$, kidney $(\mathrm{F}(3,38)=0.055$, $\mathrm{P}>0.05)$ and blood $(\mathrm{F}(3,36)=1.52, \mathrm{P}>0.05)$ (Table 1). The results in brain and kidney are in agreement with the absence of an effect of lead exposure on cerebral and renal ALA-D activity reported by Rocha et al. (6). Our data

\begin{tabular}{|c|c|c|c|c|}
\hline & Saline & $\mathrm{Pb}^{2+}$ & $\mathrm{Zn}^{2+}$ & $\mathrm{Pb}^{2+}+\mathrm{Zn}^{2+}$ \\
\hline Brain & $N=10$ & $N=11$ & $N=11$ & $N=9$ \\
\hline Specific activity & $9.53 \pm 0.98$ & $9.77 \pm 1.36$ & $9.29 \pm 1.30$ & $7.79 \pm 1.46$ \\
\hline Reactivation index & $13.67 \pm 3.41$ & $33.33 \pm 4.34 *$ & $19.29 \pm 4.05$ & $38.90 \pm 8.24 * *$ \\
\hline Kidney & $N=11$ & $N=11$ & $N=10$ & $\mathrm{~N}=10$ \\
\hline Specific activity & $38.79 \pm 5.93$ & $36.31 \pm 2.93$ & $37.30 \pm 4.09$ & $37.01 \pm 4.63$ \\
\hline Reactivation index & $15.80 \pm 2.66$ & $33.50 \pm 2.97^{* *}$ & $14.80 \pm 1.43$ & $37.60 \pm 2.67^{* *}$ \\
\hline Blood & $N=9$ & $N=11$ & $N=11$ & $N=9$ \\
\hline Specific activity & $171.59 \pm 13.83$ & $123.23 \pm 17.51$ & $154.55 \pm 14.86$ & $173.13 \pm 28.48$ \\
\hline Reactivation index & $31.07 \pm 4.61$ & $63.95 \pm 3.73^{* *}$ & ${ }^{k} \quad 32.30 \pm 5.49$ & $56.43 \pm 5.93^{* *}$ \\
\hline
\end{tabular}

Data are reported as mean \pm SEM. Eight-day-old rats were treated intraperitoneally with saline, lead acetate $\left(\mathrm{Pb}^{2+}, 8 \mathrm{mg} / \mathrm{kg}\right)$ and/or zinc chloride $\left(\mathrm{Zn}^{2+}, 2 \mathrm{mg} / \mathrm{kg}\right)$ for 5 consecutive days and the enzymatic assay was carried out $24 \mathrm{~h}$ after the end of treatment. Activity is reported as nmol porphobilinogen formed $\mathrm{h}^{-1} \mathrm{mg}_{\text {protein }}^{-1}$ for the cerebral and renal enzyme and as nmol porphobilinogen formed $\mathrm{h}^{-1} \mathrm{ml}$ erythrocytes ${ }^{-1}$ for blood. ${ }^{*} \mathrm{P}<0.05$ or $* * \mathrm{P}<0.01$ compared to control (Newman-Keuls test). also demonstrated that zinc treatment did not change ALA-D activity in any of the tissues examined, in contrast to the reported activation of renal ALA-D in adult rats treated with zinc (20). Blood ALA-D activity was slightly reduced in the lead-exposed group as compared to the control group, although this reduction was not statistically significant. This result contrasts with the increase in blood ALA-D activity in rats exposed to lead acetate during the second stage of rapid postnatal growth (6). In fact, both a reduction and an increase in blood ALA-D activity in lead-exposed rodents have been reported $(7,11,12)$. The studies that report an increase in blood ALA-D elicited by lead exposure have attributed it to an increase in ALA-D synthesis $(11,12)$. The group exposed to lead + zinc did not exhibit any decrease in blood ALA-D activity. However, considering that the absence of a significant effect of lead alone on the enzyme activity was observed, we cannot conclude that zinc had an antagonistic effect. The ability of zinc to prevent ALA-D inhibition by lead has been a matter of extensive study, and contradictory findings have been reported. Considering that zinc is able to induce the synthesis of metallothionein, it is possible that pretreatment with zinc would be more efficient in preventing the effects of lead administration on ALA-D activity (20). The induction of this zinc-binding protein in target tissues such as brain and kidney, but not blood, during development may play a role in the effects observed in our study. In fact, competition between zinc and lead for binding to proteins such as metallothionein and ALA$\mathrm{D}$ has been demonstrated and lead appears to be more potent than zinc in binding to ALAD (2).

One-way ANOVA revealed a significant effect of lead and/or zinc treatment on the reactivation index with DTT of ALA-D activity in brain $(\mathrm{F}(3,37)=5.15, \mathrm{P}<0.01)$, kidney $(\mathrm{F}(3,38)=21.34, \mathrm{P}<0.01)$ and blood $(\mathrm{F}(3,36)=10.39, \mathrm{P}<0.01)($ Table 1). Post 
hoc Newman-Keuls comparisons showed that the reactivation index with DTT in brain, kidney and blood was significantly higher in the groups exposed either to lead alone or to lead + zinc as compared to the control group. This is an interesting finding that contrasts with the absence of effect of lead and lead + zinc on ALA-D specific activity. The reactivation index with DTT has been shown to be a sensitive indicator of ALA-D inhibition by lead and/or by oxidation of sulfhydryl groups of the enzyme which are important in its catalytic activity (13). One possibility which would account for the higher reactivation as for index with DTT in lead-exposed rats, as well as for the absence of lead effect on ALA-D specific activity, is that lead treatment may have produced a dual effect on ALA-D, i.e., an inhibition of the enzyme associated with an increase in its synthesis as a compensatory mechanism. The doses of lead acetate that are able to inhibit ALA-D activity in 13-day-old rats have been shown previously, with $\mathrm{IC}_{50}$ for inhibition of ALA$\mathrm{D}$ by lead being 3.9, 4.4 and $0.8 \mu \mathrm{M}$ for brain, kidney and blood, respectively (6). We do not have the lead concentrations attained in 13-day-old rats. However, our group has data showing that 21-day-old rats exposed to lead acetate $(8.0 \mathrm{mg} / \mathrm{kg}$, ip $)$ during the second stage of rapid postnatal brain growth have a lead concentration of approximately $0.5,4.0$ and $0.8 \mu \mathrm{M}$ for brain, kidney and blood, respectively. In view of these data, the lead concentrations attained in our study seem to have reached inhibitory levels. Moreover, even if the lead concentration attained in the tissues was lower than the one required to inhibit ALA-D, we should bear in mind that lead may accumulate in specific cellular microenvironments and that lead has more direct access to proteins located in the cytosol, e.g., ALA-D, compared to other cellular compartments (20). The reduction in heme concentration is believed to have a great impact on young rats in the phase of development in which lead/zinc treatments were imposed, which corresponds to a stage of rapid postnatal brain development and intense cellular metabolism. Finally, independently of the mechanism underlying the enhancement in the reactivation index with DTT in lead-exposed rats, zinc was not able to protect against the effects of lead on ALA$\mathrm{D}$ in the regimen employed in this study.

Two-way ANOVA for repeated measures used to analyze the latency to complete the negative geotaxis showed a significant effect of age $(F(4,176)=21.93, \mathrm{P}<0.01)$. No significant effect of treatment $(\mathrm{F}(3,44)=$ $0.03, \mathrm{P}>0.05)$ or of treatment $\mathrm{x}$ age was observed $(\mathrm{F}(12,176)=0.58, \mathrm{P}>0.05)$ (Table 2). Post hoc analysis by the Newman-Keuls test showed a significant reduction in latency in 13-day-old rats compared to 9-dayold rats in all groups. The absence of an effect of treatment on negative geotaxis suggests that the regimen of lead and/or zinc exposure did not impair the psychomotor function of suckling rats. By contrast, an impairment of negative geotaxis behavior has been reported in young rats exposed to methylmercury (5).

Thus, our lead and/or zinc exposure regimen was not sufficient to affect physical tissue parameters or motor coordination and also did not affect ALA-D specific activity. However, the reactivation index with DTT was a highly sensitive parameter to indicate

\begin{tabular}{|c|c|c|c|c|c|}
\hline & \multicolumn{5}{|c|}{ Age } \\
\hline & 9 days old & 10 days old & 11 days old & 12 days old & 13 days old \\
\hline Saline & $18.6 \pm 2.3$ & $15.5 \pm 2.1$ & $15.2 \pm 1.9$ & $15.4 \pm 2.4$ & $11.3 \pm 1.1^{*}$ \\
\hline $\mathrm{Pb}^{2+}$ & $22.3 \pm 2.7$ & $14.5 \pm 1.9$ & $14.2 \pm 1.7$ & $14.6 \pm 1.7$ & $12.0 \pm 1.4^{*}$ \\
\hline $\mathrm{Zn}^{2+}$ & $20.6 \pm 2.6$ & $16.7 \pm 2.4$ & $13.8 \pm 1.3$ & $13.6 \pm 1.5$ & $11.2 \pm 1.0^{*}$ \\
\hline $\mathrm{Pb}^{2+}+\mathrm{Zn}^{2+}$ & $21.8 \pm 2.5$ & $16.7 \pm 1.8$ & $14.9 \pm 1.5$ & $13.5 \pm 1.2$ & $11.4 \pm 1.0 *$ \\
\hline
\end{tabular}

Data are reported as mean \pm SEM . Eight-day-old rats were treated intraperitoneally with saline, lead acetate $\left(\mathrm{Pb}^{2+}, 8 \mathrm{mg} / \mathrm{kg}\right)$ and/or zinc chloride $\left(\mathrm{Zn}^{2+}, 2 \mathrm{mg} / \mathrm{kg}\right)$ for 5 consecutive days. The geotaxis response was assessed $24 \mathrm{~h}$ after the start of treatment until $24 \mathrm{~h}$ after the end of treatment. * $\mathrm{P}<0.01$ compared to 9-day-old rats (Newman-Keuls test). $\mathrm{N}=8$ to 12 in each group. 
an effect on the enzyme that we propose might be used to monitor the effects of lead on ALA-D. If we had measured only ALA-D activity, as done in many studies in the litera- ture, we would have concluded that the treatment had no effect on the enzyme, which seems not to be the case.

\section{References}

1. Al-Saleh IAS (1994). The biochemical and clinical consequences of lead poisoning. Medical Research Reviews, 14: 415-486.

2. Bressler J, Kim K, Chakraborti T \& Goldstein $G$ (1999). Molecular mechanisms of lead neurotoxicity. Neurochemical Research, 24: 595-600.

3. Davis J M, Otto DA, Weil DE \& Grant LD (1990). The comparative developmental neurotoxicity of lead in humans and animals. Neurotoxicology and Teratology, 12: 215-229.

4. Gottlieb A, Keydar I \& Epstein HT (1977). Rodent brain growth stages: An analytical review. Biology of the Neonate, 32: 166176.

5. Rocha JBT, Freitas AJ, Marques MB, Pereira ME, Emanuelli $T \& \&$ Souza DO (1993). Effects of methylmercury exposure during the second stage of rapid postnatal brain growth on negative geotaxis and on delta-aminolevulinate dehydratase of suckling rats. Brazilian J ournal of Medical and Biological Research, 26: 1077-1083.

6. Rocha JBT, Pereira ME, Emanuelli T, Christofari RS \& Souza DO (1995). Effect of treatment with mercuric chloride and lead acetate during the second stage of rapid postnatal brain growth on $\delta$-aminolevulinic acid dehydratase (ALA-D) activity in brain, liver and blood of suckling rats. Toxicology, 100: 27-37.
7. Satija NK \& Vij AG (1995). Preventive action of zinc against lead toxicity. Indian J ournal of Physiology and Pharmacology, 39: 377-382.

8. Winneke GMD (1996). Zinc to prevent lead poisoning. Canadian Medical Association J oumal, 154: 1622-1623.

9. Choi DW \& Koh J Y (1998). Zinc and brain injury. Annual Review of Neuroscience, 21: 347-375.

10. Bechara EJ H (1996). Oxidative stress in acute intermittent porphyria and lead poisoning may be triggered by 5 -aminolevulinic acid. Brazilian J ournal of Medical and Biological Research, 29: 841-851.

11. Fujita H, Orii $Y \&$ Sano S (1981). Evidence of increased synthesis of $\delta$-aminolevulinic acid dehydratase in experimental lead-poisoned rats. Biochimica et Biophysica Acta, 678: 39-50.

12. Kajimoto $M M$, Kondo $M$, Niwa $M$, Suzuki T, Kimura H, Sasaki A \& Urata G (1983). Increase of $\delta$-aminolevulinic acid dehydratase (ALAD) in rat erythrocytes in lead poisoning. Archives of Toxicology, 52: 111.

13. Tsukamoto $\mathrm{I}$, Yoshinaga $T \&$ Sano $\mathrm{S}$ (1979). The role of zinc with special reference to the essential thiol groups in deltaaminolevulinic acid dehydratase of bovine liver. Biochimica et Biophysica Acta, 570: 167-178.

14. Rodrigues ALS, Rocha J BT, Pereira ME \&
Souza DO (1996). $\delta$-Aminolevulinic acid dehydratase activity in weanling and adult rats exposed to lead acetate. Bulletin of Environmental Contamination and Toxicology, 57: 47-53.

15. Haeger-Aronson B \& Schutz A (1976). Antagonistic effect in vivo of zinc on inhibition of delta-aminolevulinic acid dehydratase by lead. Archives of Environmental Health, 31: 215-220.

16. Chiba M \& Kikuchi M (1984). The in vivo effects of manganese and zinc on deltaaminolevulinic acid dehydratase activity inhibited by lead. Toxicology Letters, 20: 143-147.

17. Sassa S (1982). Delta-aminolevulinic acid dehydratase assay. Enzyme, 28: 133-145.

18. Lowry $\mathrm{OH}$, Rosebrough NJ, Farr AL \& Randall RL (1951). Protein measurement with the Folin phenol reagent. J ournal of Biological Chemistry, 193: 265-275.

19. Rodrigues ALS, Rocha J BT, Mello CF \& Souza DO (1996). Effect of perinatal lead exposure on rat behaviour in open field and two-way avoidance tasks. Pharmacology and Toxicology, 79: 150-156.

20. Goering PL \& Fowler BA (1987). Metal constitution of metallothionein influences inhibition of $\delta$-aminolevulinic acid dehydratase (porphobilinogen synthase) by lead. Biochemical J ournal, 245: 339-345. 